\title{
Chandra Anuloma Viloma Pranayama modifies Cardiorespiratory Functions
}

\author{
Prakash $S^{1}$, Upadhyay-Dhungel $\mathrm{K}^{2}$ \\ Think Tank Foundation, Nepal \& Janaki Medical College, Nepal \\ 1Fellow Researcher, Think Tank Foundation \& Assistant Professor, Janaki Medical College \\ ${ }^{2}$ Research Supervisor, Think Tank Foundation \& Associate Professor, Janaki Medical College
}

\begin{abstract}
Background and Objectives: In recent years, there has been considerable interest in scientific research on yoga, especially on Pranayama. Nostril breathing exercises including Alternate nostril breathing, Left nostril breathing and right nostril breathing exercises is getting attention in the east and in the west. Left nostril breathing exercises is also called Chandra Nadisuddhi Pranayama or Chandra anulomaa vilomaa Pranayama (CAV). Very few have carried out research on Chandra Anuloma Viloma Pranayama (CAV). This study was carried out to see the effects of CAV on experienced yoga practitioners and naïves.
\end{abstract}

Material and Methods: The study consisted of 36 subjects divided into two groups, first group consist of 26 medical students who were naïve and the next group consist of 10 yoga practitioners. All the subjects performed 12 rounds of Chandra Nadisuddhi Pranayama in each session for 24 days. Variables were entered into SPSS Program and were analyzed.

Results: This study depicts fall in Pulse rate, respiratory rate, systolic blood pressure and Diastolic blood pressure after CAV Pranayama in both Naïves and Yoga practitioners. But the significant drop was observed in SBP only (at $\mathrm{p}<0.05$ ) among Naives and in all parameters except respiratory rate among Yoga Practitioners.

Conclusion: The effect of the Chandra Anuloma Viloma (CAV) in this study was more eminent in the yoga practitioners than in the naïve group.

Key words: Pranayama, Left nostril breathing, Chandra Anuloma Viloma (CAV), cardio-respiratory function

\section{INRODUCTION}

Traditional practices of Yoga documented in numerous historical and contemporary writings, suggest that individual modification of breathing patterns under the direction and guidance of a proper teacher can lead to positive, subjective, affective, cognitive and behavioral changes These practices endow with prospect to cope in a more empowered way to life's stresses and improve health outcomes [1].

Yogic practices develops various physiological changes which involves physical, mental and spiritual task in a 
comprehensive manner, bringing about behavioural changes and claimed to have sound scientific basis [2]. Static postures of yogasana and controlled rhythmic breathing of Pranayamas involve minimal body movements and result in maximal physical and mental relaxation. The proprioceptive involvement in a well coordinated fashion with mentally relaxed state in the yogic practices helped the subjects to achieve the improvement of psychological and psychomotor components. The improvement in physiological and psychological functions improves the feeling of subjective mental well-being [3].

Pranayama is one of the eight limbs of Asthanga Yoga and includes different respiratory techniques and were used as important lifestyle techniques by ancient yogis. Now a day's such techniques is being used as alternative medicine and therapy and is becoming popular day by day. It is no longer the practices of yogis and Monks. Yoga therapy is being used and prescribed by medical practioners to treat various physical and psychological ailments $[4,5]$. Slow yogic breathings or slow pranayams like Savitri Pranayama, Sitkari , Anuloma Viloma Pranayama, Nadi sudhhi are accredited as most prominent practical relaxation techniques which can be used as an adjunctive means of treatment to recover symptoms associated with autonomic imbalances[6,7], cardiovascular diseases as hypertension and respiratory disorders[6,8] like asthma and other COPD and various psychological stress related disorders $[9,10]$. Short term effect of slow breathing Pranayama includes decreased heart rate, blood pressure [6, 11] and oxygen consumption [12] where as Long term effect of pranayamic breathing includes improvement in autonomic nervous system $[13,14]$.

In recent years, there has been considerable interest in scientific research on Pranayama in the east and in the west. The focus of the scientific studies is mainly on Nostril breathing Pranayama which includes mainly Alternate nostril breathing Pranayama followed by effect of individual Left Nostril breathing Pranayama and Right Nostril breathing Pranayama. They are all known to affect the cardiopulmonary activities and autonomic functions $[15,5,6,16,19]$.

Chandra Anuloma Viloma (CAV) Pranayama which included breathing through Left nostril alone is also explained as Chandra Nadisuddhi Pranayama and expected to have cooling down or parasympathetic effect in the body [5]. Few researchers have reported the effect of Left nostril breathing exercises [17, 18]. Malhotra et al studied the effect of CAV Pranayama in Naïve and Yoga Practioners both and the study was limited in single volunteer in each group [19]. This study is carried out as extension of that study in several volunteers. This study is carried out to see the acute effect of CAV Pranayama on heart rate and Blood pressure of Naives and Yoga practitioners.

\section{MATERIALS AND METHODS}

This study was conducted by Think Tank Foundation, Jorpati, Kathmandu, Nepal in collaboration with Department of Physiology and Dept of Biochemistry, JMCTH, Janakpur Nepal. Ethical clearance was obtained from the Institutional Ethics Committee prior to the commencement of the study. The health of the participants was assessed by history and clinical examination. Participants who were clinically healthy volunteers were 
included in this study. Smokers and alcoholics, individuals with mechanical or infective nasal blockage, oro-pharyngeal infections and with any major systemic disorders especially respiratory and cardiovascular disorders were excluded. Volunteers were divided into two groups, first group consist of 26 volunteers. They were naïves for yoga or inexperienced person, who had just started practicing the techniques of Pranayama or have not done Pranayama regularly. The next group consists of 10 yoga practitioners who had been practicing yoga and Pranayama for more than 5 years. All the subjects attended the study voluntarily. The participants were briefed about the procedure and written informed consent was obtained from each of them prior to being recruited for the study. The study was conducted in a temperature controlled, noise and light reduced peace place. All the subjects performed 12 rounds of Chandra nadisuddhi Pranayama in each session. Variables were measured Pre and Post each Pranayama session. The data were analyzed using SPSS statistical software.

\section{Chandra Nadisuddhi Pranayama}

The participants were seated in a comfortable sitting posture, with back straight while practicing the Pranayama. Chandra nadisuddhi Pranayama starts with closing the right nostril with the thumb of the right hand, followed by hold and exhalation through the left nostril and inhalation slowly through the same nostril [20]. This forms one round of Chandra nadisuddi Pranayama (CAV). There is a comfortable pause (no forceful holding) between the inhalation and the exhalation. The Pranayama was carried out by volunteer in comfortable manner. The heart beat rate was taken immediately before and immediately after twelve cycles of the left nostril breathing. The heart beat rate was measured by counting radial pulse. The readings were taken each day for each participant in the morning hours between 8.00 A.M and 10.00 A.M and in the evening from 4.00 P.M to 6.00 PM for 24 days. A total of 48 readings of each subjects were taken. The Pranayama session was performed before meals. The subjects were told not to hold the breath for an uncomfortably long period in each round.

\section{RESULTS}

All data were entered in SPSS statistical software and analyzed and are discussed below in Table 1, 2 and 3 .

Demographic characteristics of the study subjects

The age of Naïve group and Yoga group were (22.24 \pm 2.21 and $24.2 \pm 1.04)$, weight (58.42 \pm 2.52 and $64.12 \pm 1.52$, height (167.24 \pm 3.46) and others demographic details are presented in Table 1.

Table 1: The demographic details of both groups of subjects

\begin{tabular}{|c|c|c|}
\hline \multirow{2}{*}{ Parameters } & \multicolumn{2}{|c|}{ Mean \pm SD } \\
\cline { 2 - 3 } Age (yrs) & Naïve group & Yoga group \\
\hline Weight (Kg) & $22.24 \pm 2.21$ & $24.2 \pm 1.04$ \\
\hline Height (cm) & $167.24 \pm 3.46$ & $164.04 \pm 1.04$ \\
\hline BMI (Kg/m ${ }^{2}$ ) & $20.93 \pm 0.92$ & $23.83 \pm 0.86$ \\
\hline $\begin{array}{c}\text { Practice of yoga } \\
\text { (yrs) }\end{array}$ & $>5$ years & $<1$ months \\
\hline
\end{tabular}

SD, standard deviation; <, less than; >, greater than

Physiological parameters, before and after CAV Pranayama among Naïve

There was decrease in Pulse rate (PR), respiratory rate (RR), systolic blood pressure (SBP) and Diastolic blood pressure (DBP) after CAV Pranayama. But the significant fall was seen in SBP only (at $p<0.05$ ) (Table 2). 
Table 2: Different physiological parameters, before and after CAV Pranayama among Naive

\begin{tabular}{|l|c|c|}
\hline \multirow{2}{*}{ Parameters } & \multicolumn{2}{|c|}{ Mean \pm SD } \\
\cline { 2 - 3 } & Pre & Post \\
\hline PR (per min) & $79.64 \pm 4.55$ & $75.91 \pm 3.80$ \\
\hline RR (per min) & $17.16 \pm 0.91$ & $15.74 \pm 0.65$ \\
\hline & $117.54 \pm$ & $110.2 \pm$ \\
SBP (mm Hg) & 2.16 & $1.64^{*}$ \\
\hline DBP (mm Hg) & $78.02 \pm 2.12$ & $76.04 \pm 1.26$ \\
\hline
\end{tabular}

*, significant at $\mathrm{p}<0.05$

Physiological parameters, before and after CAV Pranayama among Yoga Practitioner

There was significant fall in Pulse rate (PR), systolic blood pressure (SBP) and Diastolic blood pressure (DBP) and insignificant drop in respiratory rate (RR) after CAV Pranayama among Yoga practitioners (Table 3).

Table 3: Different physiological parameters, before and after CAV Pranayama among Yoga Practitioner

\begin{tabular}{|c|c|c|}
\hline \multirow{2}{*}{ Parameters } & \multicolumn{2}{|c|}{ Mean \pm SD } \\
\cline { 2 - 3 } & Pre & Post \\
\hline PR (per min) & $74.71 \pm 1.95$ & $67.04 \pm 1.71^{*}$ \\
\hline RR (per min) & $16.21 \pm 1.10$ & $15.07 \pm 0.93$ \\
\hline SBP (mm Hg) & $118.24 \pm 1.16$ & $112.3 \pm 1.64^{*}$ \\
\hline DBP (mm Hg) & $73.16 \pm 1.12$ & $68.02 \pm 1.26^{*}$ \\
\hline
\end{tabular}

*, significant at $\mathrm{p}<0.05$

\section{DISCUSSION}

Yogic practices, now a days is established as an alternative medicine [21] was a spiritual practices designed for the purpose of cultivating a steady mind systematized by Patanjali in his classical work, the Yoga Sutras [6]. Yoga has been defined as 'technologies or disciplines of asceticism and meditation which are thought to lead to spiritual experiences and a profound understanding or insight into the nature of existence [22]. Yogic techniques include meditation, regulation of respiration with a variety of breathing exercises and a number of physical exercises and Aasana (postures) in which the focus is more on isometric exercise [23]. Yogic exercises are thus an effective ancient method used from Vedic days to improve the mental and physical health $[5,6]$ of the young and old individuals. It streamlines the autonomic nervous system (ANS) [23, 21] and helps to improve cardio respiratory, neurological functions and, decreases the effect of stress and improves physical and mental health [24]. It also has been shown to decrease heart rate and blood pressure [25, $26,27]$. They induce relaxation response which consists of a generalized reduction in both cognitive and somatic arousal as observed in the modified activity of the hypothalamic - pituitary axis and the autonomic nervous system [28].

Yoga makes use of voluntary regulation of the breathing to make respiration rhythmic and to calm the mind. Breathing is a vital process which starts at the time of birth and stops at the death. In yogic philosophy life force or vital force is called Prana. The process of controlling the Prana is called Pranayama. Pranayama is derived from two Sanskrit words, namely, Prana, which means vital force or life energy, ayama means to prolong [29]. Versions of Pranayama vary from single nostril breathing to belly breathing. Pranayama consists of three phases: Puraka (inhalation), Kumbhaka (retention) and Rechaka (exhalation) that can be either fast or slow. So, Pranayama is the science related to essential strength supplying energy and controlling the body mind complex [22].

Pranayamic breathing exercises have been reported to affect the ANS in different ways depending on the breathing technique, duration of practice and the period of recording of the autonomic parameters [24]. Pranayama, the yogic system of breathing, is 
based on the belief that right nostril dominance corresponds to sympathetic arousal and left nostril breathing corresponds to parasympathetic arousal [27]. Pranayamic breathing practiced exclusively via either nostril has opposite effects on right nostril breathing increases sympathetic activity while left nostril decreases it. [17, 30]

When the respiratory cycle of inhalation and exhalation is completed through the left nostril alone the practice is called "Chandra Anulomaa Vilomaa Pranayam" which means a heat dissipating or cooling liberating practice [31]. This study found remarkable fall of pulse rate, respiratory rate, systolic blood pressure and diastolic blood pressure after CAV Pranayama among Naïve group but the fall was found to be significant in SBP only (at $\mathrm{p}<0.05$ ). Similar findings were also obtained in the study conducted by V. Malhotra et al. [19]. Further, The significant decrease in Pulse rate, systolic blood pressure and Diastolic blood pressure was observed after CAV Pranayama among Yoga practitioners of this study. A study conducted by Dane et al, who made their subjects exercise before studying the effect of nostril breathing on heart rate, found an increase in heart rate with both left probably due to the overall effect of exercise on heart rate [32]. A reduction in heart rate after left nostril breathing has been reported in one of the study[33], while others have reported no significant changes in the heart rate after left or right nostril breathing exercises.[34,35] Jain et al, working with subjects who were asked to practice single nostril breathing reported a drop in heart rate with left nostril breathing in males but not in females [36]. Left nostril breathing produced a marked decrease in sympathetic activity to the sweat glands whereas other subdivisions did not change as much relatively smaller changes in baseline oxygen consumption and heart rate [37]

Decrease in heart rate and blood pressure in subjects practicing yoga indicates predominance of the parasympathetic system and relatively reduced sympathetic tone [38, 39]. This may be due to the conditioning effects of yoga on autonomic functions and mediated through the limbic system and higher areas of central nervous system [40]. Regular practice of yoga increases the baroreflex sensitivity and decreases the sympathetic tone thereby restoring blood pressure to normal level in patients of essential hypertension [41]. Pranayama decreases basal sympathetic tone and increases basal parasympathetic activity The exact mechanism by which particular nostril breathing influences the function of the autonomic nervous system is not well known, though it has been speculated that this may occur through a neural reflex mechanism in the superior nasal meatus [42]. The physiological changes in cardiorespiratory profile with respect to Chandra Anuloma Viloma Pranayama may be due to the physiology of nostril breathing exercises having the probable relation with nostril and cerebral dominance as explained by Upadhyay- Dhungel K et al. [5, 6, 19]

\section{CONCLUSION}

Based on the analysis of the results obtained, this study concluded that the effect of CAV on different physiological parameters among Naïve group are drop in all parameters but significant drop was only seen in systolic blood pressure. Similarly, the significant fall in pulse rate, systolic blood pressure and diastolic blood pressure and insignificant fall in respiratory rate was found among Yoga practitioners. The result of the Pranayama in 
this study is more eminent in the yoga practitioners than in the naïve group. The modification of the autonomic activity might occur due to their regular habit of practicing asanas and Pranayama among yoga practitioners. Pranayama are non-invasive therapy that has several benefits in the treatment of various diseases. Further investigations are essential to recognize the exact mechanism responsible for these changes possibly by quantifying the neural circuits involved.

\section{ACKNOWLEDGEMENT}

We debt our deep appreciation and cordial thanks to Think Tank Foundation, Jorpati, Kathmandu, Nepal for encouragement towards this research and our participants for their active participation during this research.

\section{REFERENCES}

1. Tiwari S, Tiwari SK, Gehlot S et al. Outcome of breathing exercise (Pranayam) on spirometric parameters in type 2 diabetic individuals: A clinical study. J of Stress Physiol \& Biochem 2012 ; 8(4): 218-225.

2. Ray US, Mukhopadhyaya S, Purkayastha SS et al. Effect of yogic exercises on physical and mental health of young fellowship course trainees. Indian J Physiol Pharmacol 2001; 45 (1): 37-53.

3. Bharshankar JR, Bharshankar RN, Deshpande VN et al. Effect of yoga on cardiovascular system in subjects above 40 years. Indian J Physiol-Pharmacol 2003; 47 (2): 202-206.

4. Stiles M, Yoga Sutras of Patanjali. Newburyport (MA): Red Wheel/Weiser; 2001.

5. Upadhayay-Dhungel K \& Sohal A. Physiology of nostril breathing exercise and its probable relation with nostril and cerebral dominance: A theoretical research on literature. Janaki Medical College J of Med Sci 2013; 1(1):38-47.

6. Upadhyay-Dhungel K, Malhotra V, Sarkar D, Prajapati R. Effect of alternate nostril breathing exercise on cardiorespiratory functions. Nepal Med Coll J 2008; 10(1): 2527.
7. Bijlani RL. Yoga (section 17). In: Understanding Medical Physiology: A textbook of Medical students. Jaypee Brothers, New Delhi; 1995. pp871-910.

8. Bhattacharya S, Pandey US, Verma NS et al. Improvement in oxidative status with yogic breathing in young healthy males. Indian J Physiol Pharmacol 2002; 46: 349-354.

9. Brown RP \& Gerbarg PL. Sudarshan kriya yogic breathing in the treatment of stress, anxiety and depression: part 1neurophysiological model. J Alt Complement Med 2005; 11(1):189-201.

10. Ravindra PN \& Madanmohan PP. Effect of pranayam (yogic breathing) and shavasan (relaxation training) on the frequency of benign ventricular ectopics in two patients with palpitations. Int J Cardiol 2006; 108: 124- 125.

11. Singh S, Malhotra V, Singh KP, et al. Role of yoga in modifying certain cardiovascular functions in type 2 diabetic patients. J Assoc Physician Ind 2004; 52:203-206.

12. Telles $S$ \& Desiraju T. Oxygen consumption during pranayamic type of very slow-rate breathing. Indian J Med Res 1991; 94: 357-363.

13. Gopal KS, Anantharaman V, Balachandra S et al . The cardio-respiratory adjustments in 'Pranayam' with and without 'Bandhas' in 'Vajrasana'. The Ind J Med Sci 1973; 27: 686-692.

14. Iyengar BKS. Light on Pranayama: the yogic art of breathing. New York: Crossroad; 1998.

15. Malhotra V, Tandon OP, Patil R et al. Suryanadi anulomaa vilomaa Pranayama modifies autonomic activity of heart. The Joy of Yoga. Spring 2009; 8(1):1-5

16. Telles S, Nagarathana R, Nagendra HR. Physiological measures of right nostril breathing. J Alt Complement Med 1996; 2(4): 479-484.

17. Telles $S$, Nagarathana R, Nagendra HR. Breathing through a particular nostril can alter metabolism and autonomic activities Indian J Phyiol Pharmacol 1994; 38: 133-137.

18. Malhotra VM et al. Chandra anulomaa vilomaa Pranayama modifies autonomic activity of heart. BAPT 2008; 2 (1): 27-28.

19. Malhotra V, Dhungel KU, Ganga J. Does The Effect Of Pranayama Differ In Yoga Practitioner And Naive?. J of Clinical and Diagonostic Res 2010; 4: 3503-3506.

20. Naik SM. 'Pranayama' In: Yoga: An instruction booklet, Vivekananda Kendra Prakashan trust Chennai; 2007. pp 70.

21. Kumar Vijay BA, Gudge S, Patil M et al . Effects of Practice of Pranayama on Control of Life Style Disorders. J of Evolution of Med and Dental Sci 2014; 3: 8712-8718. 
22. Latha Rajendra Kumar. Role of anurom violoma pranayam in reducing stress in chronic alcoholics . IndiaPak J Physiol. 2011; 7(2):11-15

23. Dhandayutham Ashwini, Susheela Veliath, Subhasis Das et al. Effect of left \& right nostril breathing on R-R interval among adult males - A cross-sectional study. Int J of Biomedical Res 2015; 6(02): 87-91.

24.Raghura P, Ramakrishnan AG, Nagendra HR et al. Effect of two selected yogic breathing techniques $\mathrm{n}$ heart rate variability. Indian J Phyiol Pharmaco 1998; 42: 467-472.

25. Bhargava R, Gogate MGM, Ascarenhas JF. Autonomic responses to breath holding and its variations following pranayam. Indian J Physiol Pharmacol 1988; 42: 257-264

26. Tandon OP \& Tripathi Y. Yoga and its Applications. In: Best and Taylor's Physiological Basis of Medical Practice. $13^{\text {th }}$ ed. Gurgaon: Wolters Kluwer health/Lippincott Williams and Wilkins publishers; 2012. pp 1217-1230.

27. Kulkarni DD, Bera TK. Yogic exercises and health - a psycho-neuro immunological approach. Indian J Phyiol Pharmacol 2009; 53: 3-15.

28. Rajajeyakumar M, Janitha A, Balachander J, Madanmohan and Bhattacharjee M. Effect of Yogic type of Breathing (Pranayam) on different grade of Handgrip Strength among young Adults. Int J of Basic and Applied Med Sci 2014; 4 (2): 17-23.

29. Bijlani RL. Yoga (section 17). In: Understanding Medical Physiology: A textbook of Medical students. Jaypee Brothers, New Delhi; 1995. pp871-910.

30. Shannahoff- Khalsa DS, Kennedy BO. The effect of unilateral forced nostril breathing on the heart. Int J Neuro sci 1993; 73: 47-60.

31. Rajajeya MK, Amudharaj D, Bandi harikrishna, Madanmohan $\mathrm{T}$ et al. Immediate effect of Different Pranayam on Short Term Heart Rate Variability in Health Care Students A Preliminary Study. Int J of Physiol 2014; 2 (1): 39-43

32. Dane S, Caliskan E, Karasen M, et al. Effects of unilateral nostril breathing on blood pressure and heart rate in righthanded healthy subjects. Int J Neurosci 2002; 112 (1): 97-102

33. Telles S, Nagarathana R, Nagendra HR. Physiological measures of right nostril breathing. J Alt Complement Med 1996; 2(4):479-484

34. Anand BK. Yoga and medical sciences. Indian J Physiol Pharmac 1991; 35 (2): 84-87

35. Bhargava R, Gogate MG and Mascarenhas JF. Auto-nomic responses to breath holding and its variations following Pranayama. Ind J Physiol Pharmac 1988; 32 (4): 257-264.
36. Jain N, Srivastava RD, Singhal A . The effects of right and left nostril breathing on cardiorespiratory and autonomic parameters. Indian J Physiol Pharmacol 2005; 49(4):469-474

37. Singh BB Effects of Chandra-Nadi Pranayama on metabolic fitness and bone integrity Journal of the Romanian Sports Medicine Society Medicina Sportiva 2015; 11( 3): 2621-2627.

38. Backon J, Kullok S. Effect of forced unilateral nostril breathing on blink rates: relevance to hemispheric lateralisation of dopamine. Int J Neurosci 1989; 46(2): 53-59.

39. Larson G, Zaichkowsky LD, Mostofsky DI. Forced unilateral nostril breathing (FUNB) effects on the autonomic nervous system: An unsupported claim. Med Hypo1993; 41(4): 367369.

40. Mourya M, Mahajan AS, Singh NP, et al. Effect of slow-and fast-breathing exercises on autonomic functions in patients with essential hypertension. J Altern Complement Med 2009;15: 711-717.

41. Bharshankar JR, Bharshankar RN, Deshpande VN et al. Effect of yoga on cardiovascular system in subjects above 40 years. Indian J Physiol-Pharmacol 2003; 47 (2): 202-206.

42. Udupa K, Madanmohan, Bhavanani AB, Vijayalakshmi P, et al. Effect of pranayam training on cardiac function in normal young volunteers. Indian J Physiol Pharmacol 2003; 47 (1): 2733. 